\title{
A TUTELA JURÍDICA DO MEIO AMBIENTE E OS IMPACTOS AMBIENTAIS CAUSADOS POR USINAS HIDRELÉTRICAS: O CASO DA MORTANDADE DE PEIXES NO RIO ARAGUARI, AMAPÁ-BRASIL
}

\author{
LEGAL PROTECTION OF THE ENVIRONMENT AND THE ENVIRONMENTAL IMPACTS CAUSED BY \\ HYDROELECTRIC PLANTS: THE CASE OF FISH MORTALITY IN THE ARAGUARI RIVER, AMAPÁ-BRAZIL
}

\author{
Claudecilia Chaves de Oliveira Figueira ${ }^{1}$ \\ Daguinete Maria Chaves Brito ${ }^{2}$
}

\begin{abstract}
1 Advogada e Mestre em Ciências Ambientais pela Universidade Federal do Amapá (UNIFAP). E-mail: claufigueira91@gmail.com
2 Doutora em Ciências Sociais pala Universidade Federal do Amapá e Docente do Curso de Geografia, Universidade Federal do Amapá (UNIFAP). E-mail: dagnete@uol.com.br
\end{abstract}

RESUMO: Este artigo aborda teorias acerca dos impactos socioambientais causados pela construção e operação da Usina Hidrelétricas Ferreira Gomes, com enfoque sobre a mortandade de peixes ocorrida em 2014, no rio Araguari, Amapá. O objetivo é discutir os impactos socioambientais decorrentes do empreendimento frente ao princípio do Desenvolvimento Sustentável. Metodologicamente, utilizou-se abordagem qualitativa, baseada no método indutivo, com pesquisa bibliográfica e documental. Os resultados mostram que o dano ambiental está associado à operação da usina, gerando perda de biodiversidade, atingindo diretamente a atividade pesqueira, precipuamente a artesanal e de subsistência, impactando a economia local e a qualidade de vida da população.

Palavras-chave: Desenvolvimento sustentável. Impactos ambientais. Usinas hidrelétricas.

ABSTRACT: This article addresses theories about the socio-environmental impacts caused by the construction and operation of the Ferreira Gomes Hydroelectric Plant, with a focus on the fish mortality that occurred in 2014, on the Araguari River, Amapá. The objective is to discuss the socio-environmental impacts resulting from the enterprise in view of the principle of Sustainable Development. Methodologically, a qualitative approach was used, based on the inductive method, with bibliographic and documentary research. The results show that environmental damage is associated with the plant's operation, generating loss of biodiversity, directly affecting fishing activity, mainly artisanal and subsistence activities, impacting the local economy and the population's quality of life.

Keywords: Sustainable development. Environmental impacts. Hydroelectric plants.

Sumário: Introdução - 1 A Tutela do Meio Ambiente no Ordenamento Jurídico Brasileiro - 2 A Mortandade de Peixes no Rio Araguari e os Laudos Técnicos - 3 Impactos Socioambientais da Mortandade de Peixes 4 O Desenvolvimento Sustentável e as Usinas Hidrelétricas - Considerações Finais - Referências

\section{INTRODUÇÃO}

A construção de Usinas Hidrelétricas (UHE) no Brasil, se expandiu a partir de 1934 com a edição do Código das Águas e hodiernamente representa, conforme dados da ANEEL, 61,3\% do total de energia gerada no País. Entretanto, a crescente preocupação com o meio ambiente no despontar dos anos 70, do século passado, fez com que a instalação desses empreendimentos passasse a ser questionada em virtude dos prejuízos ao meio ambiente e a sociedade envolvida com a construção destes empreendimentos.

Nesse cenário, o estudo propõe uma abordagem jurídica, socioeconômica e ambiental acerca de impactos decorrentes da construção e operação de UHE frente a ausência de práticas sustentáveis de gestão, tomando por base o caso do empreendimento Ferreira Gomes Energia S.A, instalado no médio Rio 
Araguari, próximo a sede do município de Ferreira Gomes, no Estado do Amapá.

O estudo partiu da ocorrência de mortandade de peixes naquele rio, no ano de 2014 e buscou identificar a provável causa do sinistro e sua relação com as atividades da referida UHE, bem como os impactos ao equilíbrio ambiental. A premissa metodológica utilizada partiu de uma abordagem predominantemente qualitativa, baseada no método indutivo. Utilizou-se a pesquisa bibliográfica e documental, bem como dados secundários fornecidos pelos órgãos públicos envolvidos no caso.

$\mathrm{O}$ artigo estruturou-se, inicialmente, pela abordagem acerca da tutela jurídica do meio ambiente no Ordenamento brasileiro, seguido do exame técnico-teórico sobre as atividades de cunho impactante à luz do equilíbrio ambiental a partir da avaliação técnica do caso, baseada em laudos periciais, aliado a uma abordagem socioambiental do legado da mortandade de peixes no rio Araguari. Em última análise, se discutiu sobre o princípio do desenvolvimento sustentável e os aspectos desse paradigma de desenvolvimento econômico à luz da matriz energética nacional.

\section{A TUTELA DO MEIO AMBIENTE NO ORDENAMENTO JURÍDICO BRASI- LEIRO}

O termo meio ambiente apresenta algumas definições que variam de acordo com a perspectiva concebida. Para a ecologia trata-se de um conjunto composto pelos meios físico ${ }^{1}$ e biótico capaz de propiciar condições essenciais para o desenvolvimento de todas as formas de vida. $\mathrm{Na}$ acepção jurídica, segundo com Brasil (2002) e Sirvinskas (2011) o termo pode ser definido como um macrossistema organizado e interligado composto por aspectos biológicos e sociais, conforme disposto pela resolução n ${ }^{\circ}$ 306/2002 elaborada pelo Conselho Nacional do Meio Ambiente (CONAMA).

O meio ambiente pode ser definido também como a composição dos meios físico, formado por aspectos provenientes da natureza, cultural, caracterizado por elementos de formação da cultura de uma sociedade, artificial ou urbano, formado pela modificação artificial do meio físico mediante construções e meio ambiente do trabalho, representado pela interação do homem com seu local de trabalho (ANTUNES, 2014).

O homem depende dos recursos provenientes da natureza para manutenção de sua existência e perpetuação da espécie ao passo que a natureza está sujeita à inação antrópica para garantia de sua preservação. Os problemas ambientais vivenciados atualmente, como: mudanças climáticas, perda de biodiversidade, enchentes, chuva ácida, dentre outros, nada mais são do que uma reação ou resposta à intervenção humana no meio natural.

Por essa razão, é possível afirmar que há interação direta entre os meios natural e o social, tornandose interdependentes, pois os impactos negativos infligidos ao ambiente em decorrência da ação antrópica, muitas vezes em nome do progresso, afetam a qualidade de vida das pessoas, que depende do equilíbrio ecológico e ambiental (homem/natureza). Assim, diante da necessidade de se proteger o meio ambiente para as pessoas, em virtude de seu valor socioeconômico, o Ordenamento Jurídico Brasileiro o tutelou no artigo 225, "caput", da Constituição da República Federativa do Brasil (CRFB, 1988).

O referido dispositivo determina, em síntese, que: "Todos têm direito ao meio ambiente ecologicamente equilibrado [...] essencial à sadia qualidade de vida, impondo-se ao Poder Público e à coletividade o dever de defendê-lo e preservá-lo para as presentes e futuras gerações” (BRASIL, CRFB, 1988, art. 225). Frise-se que essa norma traz em seu bojo preceitos inovadores para a ordem social, pois afirma que qualquer pessoa, indistintamente, tem direito de usufruir de um meio ecologicamente equilibrado. Trouxe consigo, também, a responsabilidade de preservação de recursos ambientais para as futuras gerações.

Benjamin (2011) explica o referido dispositivo constitucional sob a ótica do antropocentrismo mitigado intergeracional, pressuposto em que se ressalta a obrigação dos homens dessa época em oportunizar

\footnotetext{
${ }^{1}$ Para Fiorillo (2013, p. 50) “O meio ambiente em seu aspecto físico é composto pela atmosfera, elementos da biosfera, águas, solo e subsolo, enquanto que o meio biótico pela fauna e flora”.
} 
às gerações futuras igualdade de condições quanto ao gozo dos recursos naturais. Trata-se de considerar o meio ambiente como um bem difuso, ou seja, não pertence a ninguém individualmente, mas é de todos. Por isso, deve ser gerido com responsabilidade por grandes empreendimentos, pelo Estado e por indivíduos (sociedade) a fim de garantir a descendência futura de forma plena.

A tutela jurídica constitucional do meio ambiente natural é uma proteção finalística de preservação da vida humana e das espécies, visando à manutenção do equilíbrio ecológico e à garantia do bem-estar social. Consubstancia-se, também, num instrumento de frenagem e limitação à ação egoísta e irresponsável do homem frente aos recursos naturais. Negar o referido direito diante de ações que violem o equilíbrio ecológico configura um retrocesso ambiental, pois sem qualidade ambiental não se consegue alcançar qualidade de vida (ARAÚJO, 2007; BENJAMIN, 2012).

Conclui-se, desse modo, que além da proteção constitucional do meio ambiente a importância da tomada de consciência individual sobre o meio em que se vive também contribui para um processo coletivo de participação responsável na busca de caminhos para efetivação da transgeracionalidade, que segundo Leite (2003) é o dever imposto ao Poder Público e à coletividade no plano Internacional e Nacional de manter, preservar e defender o meio ambiente para as presentes e futuras gerações

\section{A MORTANDADE DE PEIXES NO RIO ARAGUARI E OS LAUDOS TÉCNI- $\operatorname{COS}$}

A Bacia do Rio Araguari, segundo Brito (2008) possui área aproximada de $42.711,18$ km² e o perímetro externo da bacia hidrográfica é de, aproximadamente, $1.269 \mathrm{~km}$ de extensão, suas nascentes localizamse nas serras lombada e Tumucumaque, norte do estado do Amapá e desagua no oceano Atlântico ${ }^{2}$. É a mais extensa bacia hidrográfica do estado e pertence a denominada Bacia Independente do Amapá. O rio Araguari é considerado o mais importante curso d'agua do Estado, em especial, para a geração de energia sendo possível identificar no seu percurso três grandes trechos: Curso superior ou Alto Araguari com 132 km de comprimento; Médio curso ou Médio Araguari com $161 \mathrm{~km}$ e Curso inferior ou Baixo Araguari, com 205 km (BÁRBARA et al., 2010; BRITO, 2008; CUNHA et al., 2010). As instalações das UHE Cachoeira Caldeirão, Coaracy Nunes e Ferreira Gomes estão localizadas no seu médio curso.

O locus desta pesquisa é a área de abrangência da UHE Ferreira Gomes (figura 1), construída na territorialidade do município de Ferreira Gomes, próximo a sua sede. Segundo o Instituto Brasileiro de Geografia e Estatística (IBGE), o município tinha uma população estimada, em 2019 de 7.780 (sete mil, setecentos e oitenta) pessoas e área de 4.973,852 $\mathrm{Km}^{2}$. O município foi criado pela Lei Federal no 7.639 , de 17 de dezembro de 1987 (IBGE, 2019). É neste cenário que no período de 01 de setembro a 29 de outubro de 2014 ocorreu grande mortandade de peixes, sendo que a maior parte de indivíduos resgatados se encontravam no trecho a partir da jusante do reservatório da UHE Ferreira Gomes Energia S.A, próximo a BR 156.

\footnotetext{
2 Atualmente, após a instalação e operacionalização de três UHE (Cachoeira Caldeirao, Coaracy Nunes e Ferreira Gomes), dos danos causados pela bubalinocultura, das atividades agropecuárias que são desenvolvidas na região, além da dinâmica natural do próprio rio, a sua foz está em processo de alteração e começa a desaguar no rio Amazonas.
} 


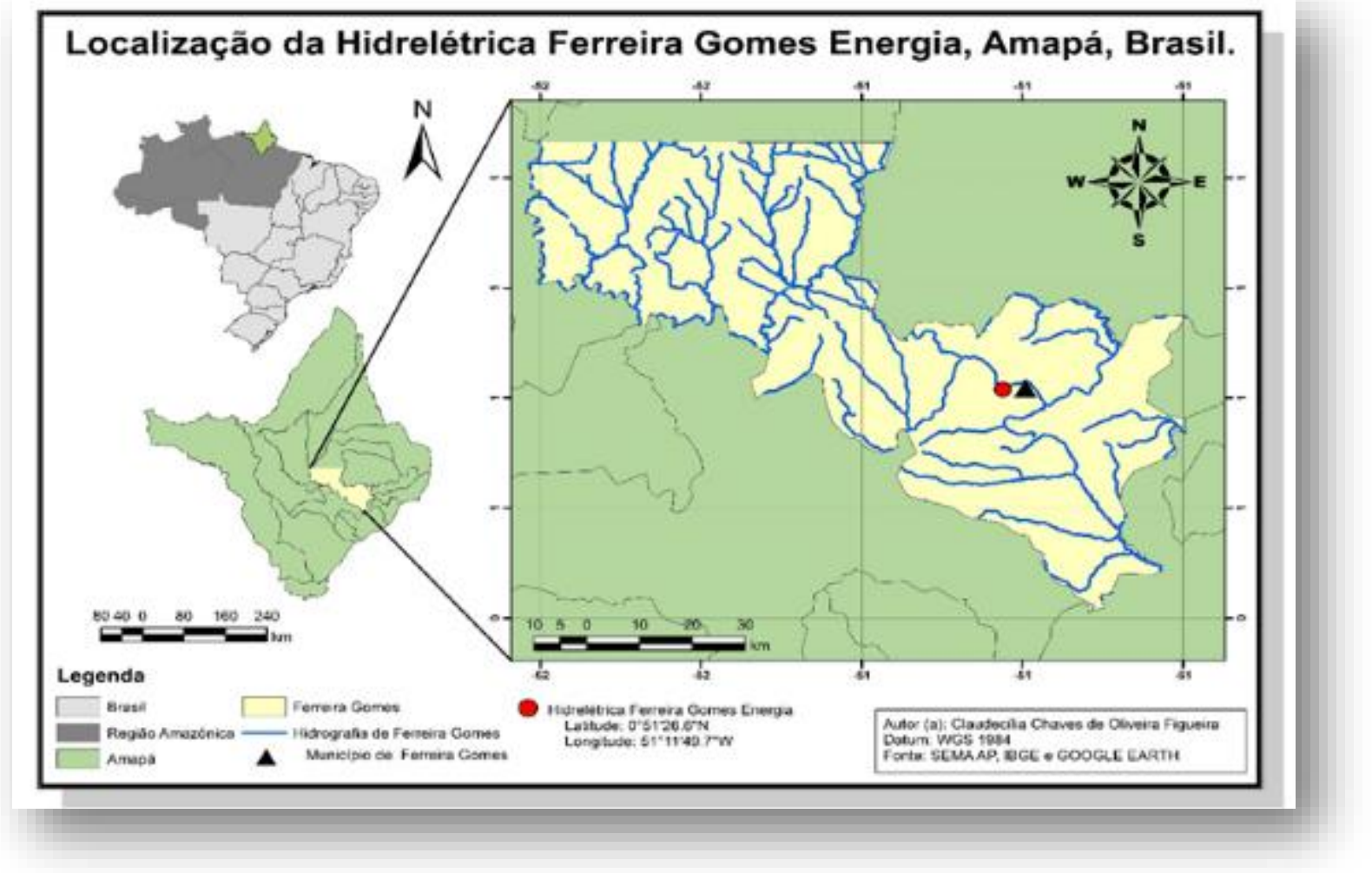

Fonte: Adaptado SEMA/AP, IBGE e Google Earth.

Diante do fato, foram acionados à época, para que diagnosticassem as causas do sinistro, o Instituto de Pesquisas Científicas e Tecnológicas do Estado do Amapá (IEPA). O órgão foi demandado pelo Ministério Público do Estado do Amapá (MPAP), a fim de subsidiar a Ação Civil Pública no $0001627-$ 41.2015.8.03.0006 promovida em face da UHE Ferreira Gomes Energia S.A, que tramita na Vara Única do Município de Ferreira Gomes/AP. O Instituto realizou estudo acerca da mortandade de peixes resultando num relatório de vinte e três páginas. E a Empresa BIOSYSTEMS Consultoria Ambiental, esta empresa privada, por sua vez, elaborou, por determinação da própria UHE Ferreira Gomes Energia S.A, um relatório de avaliação das possíveis causas da mortandade, com vinte e cinco páginas.

Segundo laudos técnicos das referidas instituições, foram resgatados e quantificados durante o período da mortandade, no trecho junto a jusante da barragem da UHE e nas imediações da orla da sede do Município de Ferreira Gomes, aproximadamente, dez mil peixes de espécies distintas, dentre os que estavam agonizando, porém vivos, e os que haviam morrido recentemente (tabela 1). É relevante mencionar, também, que não foram contabilizados os peixes em de decomposição e as carcaças, bem como não há dados quanto à aferição de peso e biomassa das espécies resgatadas. Além de não ter sido possível o resgate de indivíduos mortos nos dias 02 e 03 de outubro de 2014, em virtude de protestos de moradores na área afetada, o que prejudicou a quantificação total. 
Tabela 1 - Proporção entre espécies resgatadas no período da mortandade.

\begin{tabular}{lcc}
\hline \multicolumn{2}{c}{ Peixes resgatados no período de $01 / 09$ a $29 / 10 / 2014= \pm 10.000,00$ indivíduos. } \\
\hline \hline \multicolumn{1}{c}{ Taxonomia } & Espécimes Afetados & Vulgar \\
\hline Hypostomus ventromaculatus & $\mathrm{c}$ & $62 \%$ \\
Curimata cyprinoide & Branquinha & $15 \%$ \\
Plagiascion squamosissimus & Pescada branca & $9 \%$ \\
Cichla temensis & Tucunaré & $5 \%$ \\
Leporinus fasciatus & Aracu piau & $3 \%$ \\
Serrasalmus rhombeus & Piranha Preta & $2 \%$ \\
Espécies diversas & - & $4 \%$ \\
\hline
\end{tabular}

Fonte: BIOSYSTEMS Consultoria Ambiental, 2014.

Salienta-se que o laudo confeccionado pela BIOSYSTEMS Consultoria Ambiental (2014) associa as atividades de operação envolvendo turbinas e vertedouros da UHE Ferreira Gomes Energia S. A. à causa da mortandade, afirmando que havia

Um quadro de embolia gasosa pôde ser constatado ao longo do período em que se constatou mortes de peixes a jusante do AHE Ferreira Gomes [...].

A embolia gasosa pode decorrer de dois eventos distintos, porém geralmente associados, ou seja, (i) supersaturação de gases na água, e (ii) eventos súbitos de descompressão.

O primeiro decorre da incorporação de ar atmosférico na água que é liberado principalmente pelo vertedouro, o segundo relaciona-se tanto aos vertedouros como às turbinas e decorre de incrementos abruptos (turbulência excessiva) [...] (BIOSYSTEMS Consultoria Ambiental, 2014).

Assim, a causa mortis de alguns dos espécimes afetados pode ter decorrido de um quadro de embolia gasosa evidenciado pela formação de bolhas de gás no globo ocular, conforme demonstrado na figura 2. O diagnóstico de embolia gasosa pode ter se originado a partir da gestão de operação da UHE, haja vista constar dos referidos documentos técnicos que a abertura de comportas dos vertedouros foi realizada de forma abrupta fazendo com que o escoamento em direção a jusante do reservatório aumentasse concentrando altos níveis de oxigênio na água.

Figura 2 - Exemplar de Curimata cyprinoide apresentando bolhas nos olhos

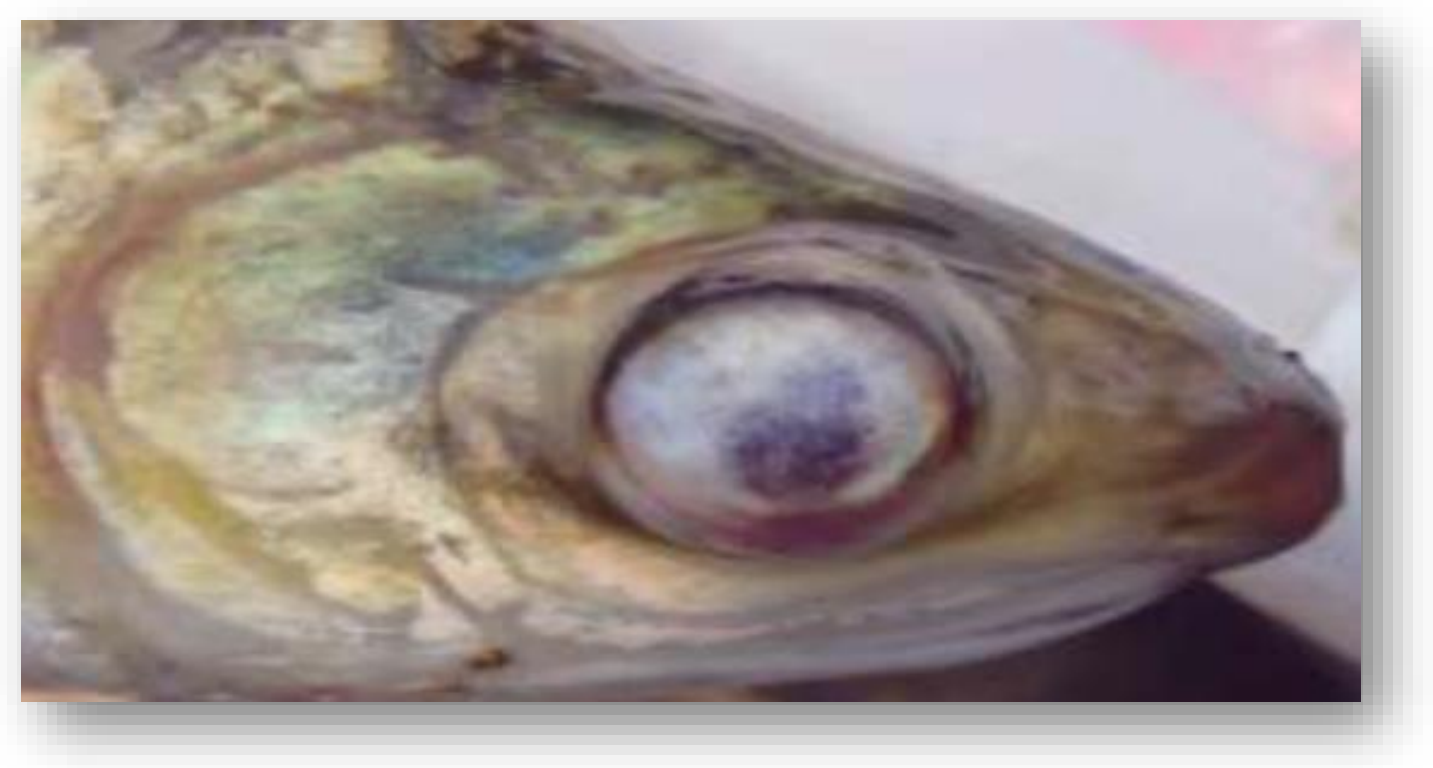


Espécimes de acaris ${ }^{3}$, que habitavam a área junto a jusante do reservatório ficaram expostos a estas condições de saturação da água por um tempo maior por isso a sua mortalidade foi massiva e constante. Por outro lado, a turbulência excessiva pode ter atraído peixes como a branquinha, a pescada branca e o tucunaré ${ }^{4}$ do fundo à superfície, ocasionando descompressão $0^{5}$, neste sentido o Relatório da Empresa afirma que

Como decorrência da turbulência os peixes são levados do fundo à superfície abruptamente, apresentando como efeito dessa descompressão atmosférica abrupta sintomas de embolia gasosa (a partir dos gases da bexiga natatória ocorre sua dilatação e rompimento), bem como hemorragias (rompimento de vasos sanguíneos) [...]. (BIOSYSTEMS Consultoria Ambiental, 2014).

Agostinho, Gomes e Pelicice (2007) recomendam a fim de se minimizar a mortandade de peixes em barragens uma gestão sustentável na operação de empreendimentos hidrelétricos por meio da abertura lenta e gradual de comportas do vertedouro. Evitando-se, com isso, a supersaturação de gás na água e também, o excesso de turbulência, ações que provocam mortandade. Essa ação mitigadora de impactos ambientais parece não ter sido observada pela Empresa Ferreira Gomes Energia S.A.

Observa-se que esse tipo de empreendimento ao conduzir suas operações fora do padrão ambiental recomendado acabam produzindo mais energia em menos tempo, o que reduz custos e aumenta lucros em detrimento da incolumidade do meio ambiente. Pelo exposto, é possível associar a causa da mortandade de peixes ocorrida em 2014 no rio Araguari, à operação do Empreendimento Hidrelétrico Ferreira Gomes Energia S.A.

\section{IMPACTOS SOCIOAMBIENTAIS DA MORTANDADE DE PEIXES}

A ictiofauna brasileira segundo Machado, Drummond e Paglia (2008) é a mais rica em número de espécies de peixes de água doce do mundo, abrigando em torno de $25 \%$ (vinte e cinco por cento) das espécies de todo o planeta. Segundo estes autores, a alta diversidade de peixes de água doce no Brasil deve-se principalmente à presença de diversos grandes sistemas hidrográficos, como o da bacia amazônica e a bacia independente do Amapá, por exemplo, na qual está inserido o Rio Araguari.

As espécies afetadas pela mortandade de peixes em 2014, na área de abrangência da UHE Ferreira Gomes, possuem função tanto ecológica quanto socioeconômica para a região. Os acaris espécie mais acometida, desempenham relevante papel na ciclagem dos nutrientes nos ecossistemas aquáticos proporcionando uma dieta favorável às demais espécies (PESSOA et al., 2013). A branquinha, por sua vez, exerce imprescindível papel ecológico na cadeia alimentar, pois em virtude de seu pequeno porte constitui alimento para espécies predadoras de grande porte, como tucunarés (COSTA et al., 2008).

O número significativo de indivíduos afetados que juntos totalizam 77\% (setenta e sete por cento) pode constituir um fator de risco para o equilíbrio ictiológico do rio Araguari. Além deste aspecto, o evento danoso ocorreu nos meses de setembro e outubro, ou seja, durante o ciclo reprodutivo de acaris e branquinhas, que possuem períodos de desova prolongado, estendendo-se de junho a dezembro (CAMARGO e LIMA JUNIOR, 2004). Por via de consequência a interrupção do ciclo reprodutivo das referidas espécies propicia falhas na reprodução, o que pode levar os estoques naturais à depleção ou mesmo à extinção, resultando em prejuízo à biodiversidade regional.

Espécies como pescada branca e tucunaré, que são peixes de médio a grande porte, a maioria predadores de topo, com importante papel na cadeia alimentar das águas (ARAÚJO et al., 2009) totalizaram 14\%

\footnotetext{
${ }^{3}$ Hypostomus ventromaculatus (Boeseman, 1968), espécie sedentária, prefere habitats de fundo rochoso e com baixa profundidade para penetração de luz (PESSOA et al., 2013).

4 Taxonomia: Curimata cyprinoide (Linnaeus,1766), plagiascion squamosissimus (Heckel,1840) e cichla temensis (Humboldt, 1821), respectivamente.

${ }^{5}$ Consiste na rápida diminuição da pressão e ocorre quando os peixes que habitam o fundo do rio, abaixo de barragens, sob alta pressão hidrostática são levados instantaneamente à superfície onde há baixa pressão (DIAS et al. 2015).
} 
(quatorze por cento) da mortandade, percentual preocupante porque são considerados importantes recursos pesqueiros e é a base da alimentação dos munícipes.

Registre-se, que durante o período do sinistro ambiental essas espécies não estavam em fase de desova, que ocorre de dezembro a fevereiro. No entanto, a quantidade considerável de indivíduos resgatados no evento pode ter reduzido a população desse grupo, que já possui ciclo reprodutivo prejudicado pela criação de barragens em virtude de sua característica migradora (CAMARGO e LIMA JUNIOR, 2004).

A redução populacional de espécies migradoras, como pescada branca e tucunaré, atinge diretamente a atividade pesqueira, precipuamente a artesanal e de subsistência, corriqueira no município de Ferreira Gomes, pois a diminuição e até mesmo a extinção dessas espécies impactam a economia local e modifica a qualidade de vida da população, que depende desses recursos para manutenção de sua subsistência.

Por outro enfoque, um ato causador de degradação do meio ambiente desvelado no dano ambiental faz emergir a necessidade legal de responsabilizar os agentes causadores em todas as esferas sancionatórias previstas no Ordenamento Jurídico pátrio - penal, civil e administrativa, uma vez que o dano ambiental reverbera sobre gerações presentes e futuras. A responsabilidade ambiental funda-se no não compartilhamento dos prejuízos pela sociedade -, ou seja, as atividades econômicas devem internalizar e responder por esses prejuízos (RODRIGUES e ARAÚJO, 2017).

Nesse sentido, a degradação ambiental decorrente das atividades da UHE tem sido amplamente discutida pelos Tribunais brasileiros. O entendimento firmado é de que a responsabilidade pela preservação e manutenção do equilíbrio ambiental deve ser do empreendimento, isto é, as Empresas responsáveis pelo dano ecológico têm o dever de promover o reequilíbrio ecológico, consoante se infere do aresto do Tribunal Regional Federal da $1^{\circ}$ Região, no julgamento da Ação Civil Pública n 0002287-40.2002.4.01.3802, pela Desembargadora Federal Selene Maria de Almeida, como pode ser observado a seguir.

DIREITO AMBIENTAL. AÇÃO CIVIL PÚBLICA. ACIDENTE OCORRIDO EM OPERAÇÃO DE MANUTENÇÃO DE TURBINA DA USINA DE PORTO COLÔMBIA. VIOLAÇÃO DO ART. 3, IV DA LEI 6.938/81. MORTE DE 4.000 QUILOS DE PEIXE. RESPONSABILIDADE CIVIL SUBJETIVA. CULPA. INOCORRÊNCIA DE CASO FORTUITO OU FORÇA MAIOR. NECESSIDADE DA REALIZAÇÃO DE ESTUDO TÉCNICO PARA ESTIPULAR CRITÉRIOS PREVENTIVOS E CRITÉRIOS PARA O CUMPRIMENTO DO JULGADO, BEM COMO PARA A OBTENÇÃO DO REEQUILÍBRIO ECOLÓGICO E DO REPOVOAMENTO DA FAUNA ICTIOLÓGICA DA REGIÃO.

No mesmo sentido inclina-se a Corte especial do mesmo Tribunal, no julgamento do Processo Civil no 0070607-48.2015.4.01.0000, pelo Desembargador Federal Hilton Queiroz:

PROCESSO CIVIL. SUSPENSÃO DE TUTELA ANTECIPADA. COMPANHIA HIDROELÉTRICA TELES PIRES S/A - CHTP. POSSIBILIDADE DE A DECISÃO DE PRIMEIRO GRAU CAUSAR GRAVE LESÃO À ORDEM E À ECONOMIA PÚBLICAS. AGRAVO REGIMENTAL NÃO PROVIDO. 1. O Ministério Público Federal ajuizou ação civil pública, com pedido de antecipação de tutela, em face da Companhia Hidroelétrica Teles Pires S/A - CHTP, requerendo a imposição de obrigação de fazer à CHTP no dever de implantar sistema anticardume capaz de impedir a mortandade de peixes gerada pelo funcionamento das turbinas da hidrelétrica. 2. O Juízo de origem concedeu a liminar para determinar à CHTP que se abstenha de levar adiante os testes de comissionamento das unidades geradoras da hidrelétrica ou de dar início à operação definitiva dessas unidades, sem antes implantar sistema anticardume, capaz de impedir a morte ou mutilação de peixes geradas pelo funcionamento das respectivas turbinas. (Fls. 312/313). 3. [...]. 4. [...]. 5. Agravo regimental não provido.

Verifica-se, portanto, que aquele que explora atividade econômica deve se colocar na posição de garantidor da preservação ambiental, isto é, os danos que dizem respeito à atividade exercida se vinculam a ela, prevalecendo, assim, a responsabilidade civil por dano ambiental. 
Tendo em vista os aspectos abordados, cumpre invocar o postulado do desenvolvimento sustentável, visto que representa fator de obtenção do justo equilíbrio entre as exigências da economia e as da ecologia, cuja observância não compromete nem esvazia o conteúdo essencial de um dos mais significativos direitos fundamentais: o direito à preservação do meio ambiente, promotor da dignidade da pessoa humana, a ser resguardado em favor das presentes e futuras gerações.

\section{O DESENVOLVIMENTO SUSTENTÁVEL E AS USINAS HIDRELÉTRICAS}

O termo Desenvolvimento Sustentável sobreveio ao debate público e político, de forma mais estruturada, em 1987 com o Relatório de Brundtland: Nosso Futuro Comum, criado pela Organização das Nações Unidas (ONU), fruto da crescente informações acerca dos resultados das interferências humanas sobre o sistema natural, que suscitou a discussão sobre a necessidade de um modelo de desenvolvimento que fosse sustentável. Entretanto, a iniciativa mundial precursora na discussão acerca da preservação do meio ambiente se deu com a Conferência de Estocolmo, realizada em 1972, na Suécia (REIS, 2005).

No plano nacional o Desenvolvimento Sustentável foi adotado pela CRFB, de 1988 no capítulo dos princípios gerais da atividade econômica - título da ordem econômica e financeira -, possui previsão no artigo 170 , inciso VI, in verbis:

Art. 170 - A ordem econômica, fundada na valorização do trabalho humano e na livre iniciativa, tem por fim assegurar a todos existência digna, conforme os ditames da justiça social, observados os seguintes princípios:

$[\ldots]$.

VI - defesa do meio ambiente, inclusive mediante tratamento diferenciado conforme o impacto ambiental dos produtos e serviços e de seus processos de elaboração e prestação (BRASIL, CRFB/1988, Art. 170 , inciso VI).

Com efeito, pode se afirmar que a autorização concedida pela CRFB/1988 em se dar tratamento diferenciado à atividade econômica conforme a potencialidade do impacto ambiental que ela possui, prioriza a defesa do meio ambiente e revela a preocupação do constituinte com o futuro da humanidade sem, contudo, impedir a exploração econômica que pode levar ao desenvolvimento.

Para Sirvinskas (2011) o referido princípio não objetiva impedir o desenvolvimento econômico, haja vista que as sociedades civilizadas o buscam porque a qualidade de vida está intimamente ligada a ele, mas, sim, conciliar a proteção do meio ambiente com o desenvolvimento socioeconômico visando à melhoria da qualidade de vida das pessoas.

Desse modo, o desenvolvimento não está ligado apenas ao crescimento econômico e à economia. Existem outras condicionantes para que o termo seja apropriado, visto que se considera, também, o acesso à educação, à saúde básica e o índice de mortalidade infantil, dentre outros fatores, como componentes do processo de desenvolvimento de uma cidade, país ou nação. O desenvolvimento gera qualidade de vida, mas nem sempre o crescimento econômico simboliza isso (COSTA e TEIXEIRA, 2017).

Nessa esteira, a Lei n 9.985/2000, que instituiu o Sistema Nacional de Unidades de Conservação da Natureza (SNUC), definiu uso sustentável dos recursos naturais, como sendo: “a exploração do ambiente de maneira a garantir a perenidade dos recursos ambientais renováveis e dos processos ecológicos, mantendo a biodiversidade e os demais atributos ecológicos, de forma socialmente justa e economicamente viável" (BRASIL, Lei n ${ }^{\circ}$ 9.985/2000, Art. 2º Inciso XI). Assim, o princípio do desenvolvimento Sustentável procura compatibilizar desenvolvimento socioeconômico e prevenção da qualidade do meio ambiente, pois a proteção do ambiente deve constituir parte integrante do processo de desenvolvimento como preceitua os princípios 3 e 4 da Declaração do Rio (ONU, 1992).

Para efetivação do desenvolvimento sustentável o Estado, as Empresas e os indivíduos devem buscar como parâmetro de ação a sustentabilidade, ou seja, a habilidade para perdurar no tempo, evitando o 
colapso das civilizações, sociedades, economias e organizações, tornando-a capazes de sustentar-se (ALMEIDA, 2002). Embora a sustentabilidade demande, muitas vezes, perda de lucro e obstaculize interesses políticos - e, por isso, ainda vem sendo implantada de modo incipiente -, ainda assim, é um compromisso de todos pautar suas ações por esse modelo de desenvolvimento.

O Setor Elétrico defende a construção de UHE como uma ação promotora de sustentabilidade, uma vez que há otimização de recursos naturais, pois são fontes limpas e eficientes de produzir energia devido ao reaproveitamento hídrico, pois, segundo a Fundação de Amparo à Pesquisa do Estado de São Paulo (FAPESP, 2010), a água usada na geração de energia volta para o rio onde será reaproveitada.

A matriz enérgica nacional é representada por mais de $60 \%$ de energia gerada por UHE. Quando se considera as matrizes energéticas mundiais, a energia eólica representa a maior parte do crescimento da geração de energia com base renovável (34\%), seguida da matriz hidroelétrica (30\%) e solares $(18 \%)$ (ANEEL, 2018; MASSIGNAN E SILVEIRA, 2017).

Observa-se, entretanto, que embora sejam um meio de produção de energia renovável a construção desses empreendimentos torna-se inviável se prioriza interesses puramente econômicos em detrimento de preceitos ambientais. A inércia ou até mesmo retrocesso no desenvolvimento econômico sustentável nacional além de não atender um objetivo constitucional, nega direitos fundamentais (MEDEIROS JÚNIOR e BARACHO, 2016). Por outro lado, Massignan e Silveira (2017) enfatizam que a visão ambiental não pode ser apenas baseada nas ciências naturais, mas também na dimensão socioambiental e cultural, e que o desenvolvimento sustentável garante, sim, mudanças sociopolíticas. Costa e Teixeira (2017) aludem que

[...] a questão ambiental, nas corporações ou sociedades industriais deve ser vista por uma nova perspectiva, em que os cuidados ambientais deixam de ser obstáculo à atividade e se torne um diferencial competitivo e estratégico para que elas se firmem no mercado, com maiores oportunidades de negócios (COSTA E TEIXEIRA, 2017, 159).

Em vista dos argumentos apresentados, o desenvolvimento sustentável só se fará presente quando o desenvolvimento econômico operar sob a égide da responsabilidade ambiental, alicerçado na informação e conscientização de que o meio ambiente incólume é um direito fundamental de presentes e futuras gerações.

\section{CONSIDERAÇÕES FINAIS}

O estudo apresentou a tutela do meio ambiente no Ordenamento Jurídico brasileiro, com previsão na CRFB/1988, leis infraconstitucionais e na jurisprudência dos Tribunais, concluindo se tratar de uma proteção finalística de preservação da vida humana e das espécies, visando à manutenção do equilíbrio ecológico e à garantia do bem-estar social. E um dos institutos para se alcançar essa proteção é o princípio do desenvolvimento sustentável, de observância obrigatória pela gestão de empreendimentos geradores de atividades impactantes, aliado a práticas de sustentabilidade.

O estudo também aferiu que a ocorrência de mortandade de peixes no rio Araguari, segundo laudos técnicos do caso, está associada à operação do empreendimento hidrelétrico Ferreira Gomes Energia S.A. E que a provável causa da mortandade de Acarí se deu por embolia gasosa decorrente da supersaturação de oxigênio na água, oriunda da vazão provocada pela abertura das comportas dos vertedouros da usina, ao passo que a mortandade de branquinhas, tucunarés e pescadas branca, também foi associada ao quadro de embolia gasosa, porém por descompressão súbita, pelo acionamento instantâneo das comportas do vertedouro.

O número significativo de indivíduos afetados, 77\% (setenta e sete por cento), torna-se um fator de risco para o equilíbrio ictiológico do rio Araguari. Além disso, a interrupção ocorrida no processo de reprodução possui consequências graves para a continuação das espécies afetadas, pois a longo prazo pode gerar o seu desaparecimento, ocasionando perda de biodiversidade regional e, por conseguinte, desequilíbrio 
ambiental.

As consequências socioeconômicas oriundas da mortandade de pescada branca e tucunaré, por sua vez, afligiu diretamente o setor pesqueiro artesanal e de subsistência dos munícipes de Ferreira Gomes, impactou a economia local e modificou a qualidade de vida da população daquela área. Observou-se que a ausência de parâmetros de sustentabilidade na condução gerencial de atividades geradoras de impactos ambientais promove mazelas multifacetadas para o meio físico e social.

Nesse contexto, o Direito posto determinar a preservação e manutenção do equilíbrio ambiental diante de degradação provocada a partir de atividades potencialmente poluidoras, pois a incolumidade do meio ambiente não pode ser comprometida por interesses de índole meramente econômica, em especial na gestão de atividades causadoras de impactos ambientais como UHE. Significa que as Empresas responsáveis pelo dano ecológico têm o dever de promover o reequilíbrio e repovoamento da fauna ictiológica afetada.

Por fim, constatou-se que o modelo de desenvolvimento sustentável somente será alcançado quando o desenvolvimento econômico operar sob a égide da solidariedade intergeracional - conscientização de que o meio ambiente é um direito fundamental da atual e futuras gerações. Portanto, sem a pretensão de se esgotar o tema sugere-se novas abordagens de pesquisa com vistas ao enriquecimento científico.

\section{REFERÊNCIAS}

AGOSTINHO, Ângelo Antônio; GOMES, Luiz Carlos; PELICICE, Fernando Mayer. Ecologia e manejo de recursos pesqueiros em reservatórios do Brasil. Maringá: Eduem, 2007.

ALMEIDA, Fernando. O bom negócio da sustentabilidade. Rio de janeiro: Nova Fronteira, 2002.

ANEEL, Capacidade de Geração do Brasil. Disponível em:< http://www2.aneel.gov.br/aplicacoes/capacidadebrasil/OperacaoCapacidadeBrasil.cfm >. Acesso em: 19 jan. 2018.

ANTUNES, Paulo de Bessa. Direito ambiental. 16. ed. São Paulo: Atlas, 2014.

ARAÚJO, Cleusa Suzana Oliveira de. et al. Parasitas de populações naturais e artificiais de tucunaré (Cichla spp.). Estudos, Jaboticabal, v. 18, n. 1, p. 34-38, Jan. /mar 2009.

ARAÚJO, Thiago Cássio D’Ávila. O estado ambiental de direito. Revista da AGU, v.6, n.14, p.167-177, dez., 2007.

BENJAMIN, Antônio Herman. Princípio da proibição de retrocesso ambiental. In: BENJAMIN, Antônio Herman. O princípio da proibição de retrocesso ambiental, Brasília: Senado Federal, 2012. Cap 02, p. $55-72$.

A natureza no direito brasileiro: coisa, sujeito ou nada disso. Revista do programa de Pósgraduação em Direito da UFC, Fortaleza, v.31, n.1, p.79-96, $1^{\circ}$ sem. 2011.

BIOSYSTEMS CONSULTORIA AMBIENTAL. Avaliação das possíveis causas da mortandade de peixes a jusante da barragem do AHE Ferreira Gomes, rio Araguari, Estado do Amapá. MacapáAM, 2014, p.03, 09.

BOESEMAN, M. 1968. The Genus Hipostomus Lacépède, 1803, and its Surinam representatives (Siluriformes: Loricariidae). Disponível em: < http://www.fishbase.org/summary/48185>. Acesso em: 03/08/2016.

BÁRBARA, Viníciu Fagundes et al. Monitoramento sazonal da qualidade da água do rio Araguari/AP. Revista Biociências. UNITAU, vol.16, n. 1, 2010. Disponível em: Acesso em: 14.09.2019.

BRASIL. Conselho Nacional do Meio Ambiente (CONAMA). Resolução no 306, de 05 de julho de 2002. Estabelece os requisitos mínimos e o termo de referência para a realização de auditorias ambientais. Disponível em: <http://www.mma.gov.br/port/conama/res/res02/res30602.html>. Acesso: 10 jan. 2018.

Constituição (1988). Constituição da República Federativa do Brasil. São Paulo: Saraiva, 2016.

Lei $\mathbf{n}^{\circ}$ 9.985, de 18 de julho de 2000. Regulamenta o art. 225, \ $1^{\circ}$, incisos I, II, III e VII da Constituição Federal, institui o Sistema Nacional de Unidade de Conservação da Natureza e dá outras providências. Disponível em: <http://www.planalto.gov.br/ccivil_03/leis/L6938compilda.hth>. Acesso: 21 jan. 2018. 
. Tribunal Regional Federal da $1^{\circ}$ Região. Direito ambiental. Ação civil pública. Acidente ocorrido em operação de manutenção de turbina da usina de porto colômbia. Violação do art. $3^{\circ}$, IV da lei 6.938/81. Morte de 4.000 quilos de peixe. Responsabilidade civil subjetiva. Culpa. Inocorrência de caso fortuito ou força maior. [...]. Apelação Cível n 2002.38.02.002259-3 MG. Relator: Desembargadora Federal Selene Maria de Almeida. DJF1, 06 ago. 2010. Disponível em: <http://arquivo.trf1.jus.br/PesquisaMenuArquivo. asp?p1 $=22874020024013802 \& p A=200238020022593 \& p N=22874020024013802>$. Acesso: 08 jan. 2018.

. Tribunal Regional Federal da $1^{\circ}$ Região. Processo civil. Suspensão de tutela antecipada. Companhia hidroelétrica Teles Pires S/A - chtp. Possibilidade de a decisão de primeiro grau causar grave lesão à ordem e à economia públicas. Agravo regimental não provido. Agravo Regimental na Suspensão de Liminar n 0070607-48.2015.4.01.000 MT. Relator: Desembargador Federal Hilton Queiroz. DJF1, 22 nov. 2016. Disponível em: <http://arquivo.trf1.jus.br/PesquisaMenuArquivo.asp?p1=706074820154010000\&pA= \&pN=706074820154010000>. Acesso: 08 jan. 2018.

. Vara Única da Comarca de Ferreira Gomes. Ação Civil Pública no 0001627-41.2015.8.03.006. Autor: Ministério Público do Estado do Amapá, Réu: Ferreira Gomes Energia S.A., 24 de agosto de 2015. Disponível em: <http://app.tjap.jus.br/tucujuris/publico/processo/index.xhtml;jsessionid=Yyg6piicl1BB Jaavf7xENbbC.host1:ha-server2>. Acesso: 09 jan. 2018.

CAMARGO, Mauricio; JÚNIOR LIMA, Walmir Mário Alves. Aspectos da biologia reprodutiva de seis espécies de peixes de importância comercial do médio rio Xingu - bases para seu manejo. Estudos, Minas Gerais, v. 3, p. 64-77, jan./fev 2004.

BRITO, Daímio Chaves. Aplicação do Sistema de Modelagem da Qualidade da Água QUAL2KW em Grandes Rios: o caso do Alto e Médio Rio Araguari - AP. Dissertação de Mestrado em Biodiversidade Tropical. PPGBIO/UNIFAP, 2008, p. 144.

COSTA, Beatriz Souza; TEIXEIRA, Angélica Cristiny Ezequiel de Avelar. Sociedades tradicionais, desenvolvimento econômico e meio ambiente: reflexões sobre a sustentabilidade como valor constitucional. Revista Direito Ambiental e Sociedade, v. 7, n. 2, p. 35-157, 2017.

COSTA, Marcio Candido da. et al. Diversidade ictiofaunística e compartimentação do rio caiapó, Goiás, por usinas hidrelétricas. Estudos, Goiânia, v. 35, n. 11/12, p. 1023-1054, nov./dez 2008.

CUNHA, Alan Cavalcanti da; BRITO, Daímio Chaves; CUNHA, Helenilza Ferreira Albuquerque. Análise se cenário da qualidade da água no rio Araguari (AP) com uso do Sistema de Modelagem QUAL2KW: impactos de hidrelétricas e urbanização. In: CUNHA, Alan Cavalcanti da; SOUZA, Everaldo Barreiros de; CUNHA, Helenilza Ferreira Alburquerque. Tempo, Clima e Recursos Hídricos: resultados do Projeto REMETAP. Macapá: IEPA, 2010, p. 119 - 134.

DIAS, Luma de Souza. et al. Avaliação da flutuabilidade neutra em peixes de água doce para estudo de mortandades em turbinas hidráulicas. In: Simpósio Brasileiro de Recursos Hídricos, 21., 2015, Brasília. Anais... Disponível em: < http://www.evolvedoc.com.br/.../download-2015-UEFQMDIwOTU4LnB $\mathrm{k} Z g=>$. Acesso: 22/12/2017.

FIORILlO, Celso Antônio Pacheco. Curso de Direito Ambiental Brasileiro. 14. ed. rev. atual. e ampl. São Paulo: Saraiva, 2013, p. 50.

FUNDAÇÃO DE AMPARO À PESQUISA DO ESTADO DE SÃO PAULO (FAPESP). Um futuro com energia sustentável: iluminando o caminho. Tradução Maria Cristina Vidal Borba. Rio de Janeiro: Academia Brasileira de Ciências, 2010.

HECKEL. 1840. Disponível em: <http://www.fishbase.org/Summary/SpeciesSummary.php?ID=4310\& AT $=$ pescada + brabra $>$. Acesso em: 22/12/2017.

HUMBOLDT. 1821. Disponível em: <http://www.fishbase.org/Summary/SpeciesSummary.php?ID=64 61\&AT=tucunar $\%$ C3\%A9>. Acesso em: 27/12/2017.

INSTITUTO BRASILEIRO DE GEOGRAFIA E ESTATÍSTICA (IBGE). Disponível em: http://ww w.ibge.gov.br/ Acesso em: 12 ago. 2019.

INSTITUTO DE PESQUISAS CIENTÍFICAS E TECNOLÓGICAS DO AMAPÁ (IEPA). Estudo acerca da mortandade de peixes no AHE Ferreira Gomes. Macapá-AM, 2014, p. 02, 08. 
LEITE, José Rubens Morato. Dano Ambiental: do individual ao coletivo, extrapatrimonial. 2. ed. rev., atual. e ampl. São Paulo: Editora Revista dos Tribunais, 2003.

LINNAEUS, C. 1766. Systema naturae per regna tria naturae, secundum classes, ordines, genera, species, cum characteribus, differentiis, synonymis, locis. Disponível em: $<$ http://www.fishbase.se/ summary/Curimata-cyprinoides.html>. Acesso em: 05/01/2018.

MACHADO, Ângelo Barbosa Monteiro; DRUMMOND, Gláucia Moreira; PAGLIA, Adriano Pereira. Livro vermelho da fauna brasileira ameaçada de extinção. Belo Horizonte, MG: Fundação Biodiversista, 2008.

MASSIGNAN, Fernando Bortolon; SILVEIRA, Paulo Caliendo da. Desenvolvimento sustentável e extrafiscalidade: o dever de intervenção estatal na economia para concretização de valores sustentáveis. Revista Direito Ambiental e Sociedade, v. 7, n. 1. P. 120-139, 2017.

MEDEIROS JÚNIOR, José Flôr de; BARACHO, Hertha Urquiza. Desenvolvimento Econômico, Equilíbrio Ambiental e Ética: desafios jurídicos e filosóficos no (do) séc. XXI. Revista de Direito Ambiental e Socioambientalismo, v. 2, n. 2, p. 86 - 106, Jul/Dez. 2016.

ORGANIZAÇÃO DAS NAÇÕES UNIDAS (ONU). Declaração do rio sobre meio ambiente e desenvolvimento. Junho de 1992. Disponível em: <http://www.onu.org.br/rio20/img/2012/01/rio92.pdf> Acesso em: 17 de jan. de 2016.

PESSOA, Emilly Kataline Rodrigues. et al. Aspectos alimentares e reprodutivos do cascudo, Hypostomus pusarum (Starks, 1913) (Osteichthyes: Loricariidae) no açude Marechal Dutra, Rio Grande do Norte, Brasil. Estudos, Macapá, v. 3, n. 3, p. 45-53, 2013. Disponível em: < http://periodicos.unifap.br/index.php/biota $>$. Acesso em: 20/12/2017.

REIS, Lineu Belico dos; FADIGAS, Eliane A. Amaral; CARVALHO, Claudio Elias. Energia, recursos naturais e a prática do desenvolvimento sustentável. Barueri, SP: Manole, 2005.

RODRIGUES, José Allankardec Fernandes; ARAÚJO, Paulo Sérgio Rodrigues de. Dano ambiental em áreas inativas de petróleo e gás: responsabilidade ambiental de agentes públicos e privados, análise à luz da doutrina e jurisprudência. Revista Direito Ambiental e Sociedade, v. 7, n. 1, p. 258-281, 2017.

SIRVINSKAS, Luís Paulo. Manual de direito ambiental. 9. ed. rev. atual. e ampl. São Paulo: Saraiva, 2011. 